\title{
Low sedimentation rate and the formation of REY-rich mud: an example from the $\mathrm{NE}$ equatorial \\ Pacific
}

\author{
Mun Gi KIM ${ }^{1}$, KisEONG HyEONG ${ }^{2}$, AND CHAN MIN \\ $\mathrm{YOO}^{3}$ \\ ${ }^{1}$ Global Ocean Research Center, Korea Institute of Ocean \\ Science and Technology, Busan, Korea. \\ mgkim@kiost.ac.kr \\ ${ }^{2}$ Global Ocean Research Center, Korea Institute of Ocean \\ Science and Technology, Busan, Korea. \\ kshyeong@kiost.ac.kr \\ ${ }^{3}$ Deep-Sea Mineral Resources Research Center, Korea \\ Institute of Ocean Science and Technology, Busan, Korea. \\ cmyoo@kiost.ac.kr
}

Deep-sea sediments with high contents of rare earth elements and yttrium (REY), termed REY-rich mud, have gained attention over the last decade for their potential as novel resources for REY. While the low sedimentation rate has been widely suggested as a key factor in their formation, no solid evidence has been presented due to the difficulty of dating sediments that generally occur on abyssal plains well below the carbonate compensation depth. Here we report bulk chemical composition and REY characteristics of a piston core collected from the northeast equatorial Pacific at $9^{\circ} 57^{\prime} \mathrm{N}$ $131^{\circ} 42^{\prime} \mathrm{W}$ (water depth: $5080 \mathrm{~m}$ ), whose chronology was established by ${ }^{10} \mathrm{Be} /{ }^{9} \mathrm{Be}$ and paleomagnetic reversal patterns. Covariation of $\mathrm{P}_{2} \mathrm{O}_{5}, \mathrm{CaO}$, and total REY contents, $\mathrm{Ca}$ to $\mathrm{P}$ ratio that approaches the composition of apatite with increasing REY content, and shale-normalized REY patterns with negative Ce anomaly and MREE-bulge are all typical of REY-rich mud, and indicate that the major host phase of REY is calcium phosphate throughout the core. The total REY concentration varied from $240 \mathrm{ppm}$ to $870 \mathrm{ppm}$, and showed negative relationship with sedimentation rate that ranged from less than $0.5 \mathrm{~m} / \mathrm{Myr}$ to more than $2 \mathrm{~m} / \mathrm{Myr}$. By combining ours with literature data from neighbouring sites, we assessed semi-quantitatively the relationship between $\sum$ REY and sedimentation rate in the region, which was also broadly comparable to previous theoretical estimates. 